\title{
A RECONSTRUÇÃO DA REALIDADE NAS CIÊNCIAS SOCIAIS*
}

FLORESTAN FERNANDES

\begin{abstract}
Nota dos Editores: O artigo "A Reconstrução da Realidade nas Ciências Sociais" foi publicado originalmente em duas partes. A primeira apareceu no número 82 da Revista Anehembi conforme a nota explicativa do texto. A segunda parte foi publicada no número 83 da mesma Revista, que saiu no mês de outubro de 1957. As duas partes do artigo foram publicadas como um capítulo do livro de Florestan Fernandes, "Fundamentos Empíricos da Explicação Sociológica", editado pela Cia. Ed. Nacional em 1959. A Editora Ática republicou o artigo completo no livro "Florestan Fernandes - Coleção Grandes Cientistas Sociais", organizado por Octavio Ianni, em 1986. A Revista Mediações, mediante autorização, publica a primeira parte do artigo apresentado no número 82 da Revista Anhembi. As notas aparecem numeradas no texto entre parênteses.
\end{abstract}

\section{I - INTRODUÇÃO}

É sabido que o cientista não lida diretamente com os fatos ou fenômenos que observa e pretende explicar, mas com instâncias empíricas, que reproduzem tais fatos ou fenômenos. A realidade não é suscetível de apreensão imediata, e sua reprodução, para os fins da investigação científica, exige o concurso de atividades intelectuais deveras complexas. Essas atividades são, naturalmente reguladas pôr normas de trabalho fornecidas pela própria ciência. Quando desenvolvidas com propriedade, elas conduzem a um conhecimento objetivo da realidade no qual esta é reproduzida, segundo graus de aproximação empírica que variam com a natureza e os propósitos das investigações, nos seus aspectos essenciais.

Isso significa que a descrição e a explicação científicas da realidade repousam, fundamentalmente, em certas operações elementares, através das quais as instâncias empíricas, que reproduzem os aspectos essenciais dos fatos ou fenômenos investigados, são obtidas, selecionadas e coligidas em totalidades coerentes. Segundo o consenso dos especialistas em lógica ou na filosofia do conhecimento científico, esse seria o domínio da técnica da investigação científica. Em termos formais, os procedimentos utilizáveis para a realização dessas operações são universais, aplicando-as portando a todos os objetos possíveis da investigação científica. As mesmas regras fundamentais orientas o ajustamento dos investigadores a diferentes situações de pesquisa, como as que apresentam na física, na química, na biologia, na psicologia ou na sociologia. Em termos operacionais, porém, são variáveis os requisitos de conhecimento objetivo da realidade. As chamadas "ciências de observação" (1), em contraste com as "ciências experimentais" (e, em particular, com as ciências que podem explorar de forma sistemática o método hipotético-dedutivo), com freqüência lidam com fenômenos cuja descrição e explicação pressupõem a reconstrução das unidades investigadas, sejam elas um órgão ou um organismo, uma pessoa ou um grupo de pessoas, uma pequena comunidade ou a sociedade industrial.

Daí a necessidade de dar maior atenção, nessas disciplinas, às questões e aos problemas que dizem respeito às operações cognitivas, pôr meio das quais os aspectos cientificamente relevantes para a descrição ou a explicação dos fenômenos investigados são documentados e elaborados interpretativamente. Sem a reconstrução do universo empírico restrito, com que tiver de operar, o investigador dificilmente poderá pôr-se em condições de descrever e de explicar os fenômenos submetidos à observação. É através da manipulação das instâncias empíricas, consideradas em conjunto, que o investigador chega a descobrir a complexa teia de ramificações da realidade, a compreender a unidade investigada como uma totalidade integrada, a formular as hipóteses alternativas básicas e a isolar as explanações descritivas e interpretativas consistentes. Em suma, embora os dados de fato nada mais sejam que a matéria prima do conhecimento científico, nas referidas disciplinas torna-se essencial acumulá-los segundo certas regras, que assegurem ao investigador a convicção subjetiva de que, nas diferentes fases da investigação, 
ele sempre terá o necessário domínio sobre as instâncias empíricas cruciais.

Todavia, graças ao desenvolvimento vagaroso e irregular da investigação empírica sistemática nas ciências sociais, pouco se progrediu na discussão dos problemas concernentes à reconstrução da realidade e às suas implicações lógicas. Os especialistas se têm devotado, com maior interesse, à constituição dos modelos de explicação da realidade social. Com isso, colocaram em primeiro plano os problemas lógicos da formação da inferência nessas ciências, os quais se impuseram primeiramente aos investigadores por causa de sua ambição de transferir os padrões do conhecimento científico à explanação dos fenômenos sociais. As únicas questões, relativas às técnicas de observação, que mereceram exame explícito e contínuo, possuíam natureza formal: quer reproduzissem os modelos de explicação das ciências naturais, quer tentassem criar modelos de explicação próprios às ciências sociais, os especialistas teriam que submeter-se às regras gerais da investigação científica. O lento progresso da pesquisa empírica sistemática é que iria pôr em relevo os problemas ligados ao modo de obter as instâncias empíricas e de combiná-las entre si, para reconstruir as unidades investigadas.

Na presente exposição, pretendemos examinar apenas algumas questões de interesse metodológico fundamental. Em que consiste o processo de observação da realidade nas ciências sociais? Os alvos teóricos das investigações repercutem, de alguma forma profunda, na reconstrução da realidade? Os cientistas sociais dispõem de meios para exercer alguma espécie de controle sobre as observações? Em que sentido a reconstrução e a explanação da realidade se condicionam ou se influenciam mutuamente nas ciências sociais? Muitas outras questões poderiam ser formuladas e discutidas, com proveito para a teoria da investigação empírica sistemática nas ciências sociais. $\mathrm{O}$ autor supõe, no entanto, que as questões indicadas são deveras importantes, situando-se entre as poucas que estão a exigir análise imediata.

\section{II.- O PROCESSO DE OBSERVAÇÃO DA REALIDADE}

O que significa "observação" nas ciências sociais? O termo é empregado, com freqüência, no sentido da linguagem corrente e alguns autores chegam, mesmo, a entendê-lo como expressão da capacidade do sujeito-investigador de "ver" as coisas (2). Se isso fosse verdadeiro, a diferença entre o conhecimento do senso comum e o conhecimento científico, a respeito dos fenômenos sociais, seria pouco precisa e insignificante. A própria legitimidade das ciências sociais poderia ser posta em dúvida: os conhecimentos que elas nos oferecessem padeceriam de defeitos similares aos do conhecimento do senso comum! Contudo, desde The Polish Peasant in Europe and America ( 3 ) ficou mais ou menos claro que os dois tipos de conhecimento se opõem tanto em termos de explicação, quanto em termos de percepção da realidade. O importante, parece, não é o que se "vê", mas o que se observa com método. Como lembra Madge ( 4 ), um pesquisador social sem treino adequado pode ver muito mas identificar pouco; enquanto um pesquisador social com idéias rígidas acaba vendo apenas os fatos que confirmam suas concepções. Além disso, é preciso não negligenciar o papel da análise como recurso de observação nas ciências sociais. Concepções estreitas, de natureza pré-científica, contribuem para manter a idéia de que a observação dos fenômenos sociais se confina aos procedimentos pelos quais são reunidos os dados brutos. Todavia, a fase verdadeiramente crucial da observação, nas ciências sociais, teminício quando o tratamento analítico dos dados permite passar das imagens sensíveis dos fenômenos para imagens unitárias ou analíticas de suas propriedades e das condições em que são produzidos.

Limitando-nos a pontos essenciais: a “observação" possui, nas ciências sociais, os mesmos caracteres e significação que nas demais ciências. Primeiro, ela transcende à mera constatação dos dados de fato. Segundo, ela envolve a complementação dos sentidos por meios técnicos. Terceiro, ela constitui o processo através do qual as instâncias empíricas, relevantes para a descrição ou a interpretação dos fenômenos sociais, são obtidas, selecionadas e coligidas. O que, sob certos aspectos, parece peculiar às ciências sociais, é a necessidade de reconstruir, empiricamente, o objeto da investigação. Isso faz com que o processo de observação seja um pouco mais complicado, nessas ciências, na fase de coligação das instâncias empíricas suscetíveis de conduzir à reprodução de elementos típicos dos fenômenos encarados em si mesmos e nas condições de sua manifestação. Seria conveniente, portanto, por em relevo porque a 
reconstrução da realidade é tão importante no estudo dos fenômenos sociais. Em qualquer setor da investigação científica, cabe à observação descobrir e por em evidência as condições de produção dos fenômenos estudados. As ciências que podem recorrer sistematicamente à experimentação, possuem meios que permitem criar ou variar, de modo artificial, as condições de produção dos fenômenos observados. A experimentação simplifica a pesquisa dos elementos que são essenciais na manifestação dos fenômenos e oferece à observação recursos que permitem concentrar as pesquisas na identificação e no levantamento desses elementos. O que importa notar é que a observação experimental confere ao investigador a capacidade de isolar, com relativa economia de trabalho e precisão, as instâncias empíricas que são cruciais para a compreensão das condições de produção do fenômeno. Graças a estas instâncias é que o investigador pode passar do "caso concreto" para "caso típico" e descrever as condições de produção do fenômeno através de fatos de significação geral. Em regra, quando o investigador consegue reunir um conjunto de evidências, que permita construir "caso típico", ele já dispõe da "explicação" do fenômeno. Daí a relativa fusão de dois momentos distintos do processo de investigação. A construção do caso típico, que se obtêm mediante a observação experimental, e a formulação de sua explicação, que constitui um processo lógico de abstração e de generalização das instâncias empíricas, interpretativamente relevantes, encontram uma expressão comum nas mesmas operações intelectuais, que culminam na descrição sintética do fenômeno.

Isso não ocorre, de forma regular, com as ciências sociais, em que ainda são muito limitadas as possibilidades de praticar a observação em condições experimentais. Os dois momentos ou fases do processo de investigação se separam com nitidez: primeiro se procede à eliminação do que é acidental, circunstancial e fortuito, mediante a construção analítica de casos típicos; só então é que se pode passar ao tratamento interpretativo das instâncias empíricas selecionadas, com o propósito de explicar os fenômenos observados. Em outras palavras, as operações intelectuais de caráter "técnico" precedem e condicionam as operações intelectuais de caráter "lógico" ( 5 ). A consistência material as premissas de uma inferência indutiva e os limites dentro dos quais ela pode ser considerada como empiricamente válida dependem, diretamente, do rigor e da precisão alcançados na conversão de dados brutos em dados típicos ou de significação geral, dadas as condições de manifestação dos fenômenos investigados.

É preciso que se entenda bem o que significa esse traço da explicação positiva da realidade nas ciências sociais, que parece ser um característico das chamadas ciências de observação em geral. Ainda que certos caracteres essenciais da realidade social sejam universais, a investigação empírica opera com fenômenos sociais concretos, que se inserem em sistemas sociais integrados mas descontínuos. O ponto de partida de qualquer investigação consiste em coligir uma documentação mais ou menos homogênea, em que estejam representados todos os fatos particulares, acessíveis ao conhecimento do investigador. É óbvio que fatos dessa ordem não são suscetíveis de tratamento científico imediato. Para que tais fatos adquiram alguma significação precisa, é necessário estabelecer o que representam nos contextos empíricos de que fazem parte. Tendo-se em vista a descontinuidade do social, isso eqüivale a determinar quais são os fatos de significação geral, nas condições em que o fenômeno investigado for considerado.

Portanto, nas ciências sociais o processo de observação abrange três espécies distintas de operações intelectuais: a) as operações através das quais são acumulados os dados brutos, de cuja análise dependerá o conhecimento objetivo dos fenômenos estudados; b) as operações que permitem identificar e selecionar, nessa massa de dados, os fatos que possuem alguma significação determinável na produção daqueles fenômenos; c) as operações mediante as quais são determinadas, isoladas e coligidas - nesse grupo restrito de fatos - as instâncias empíricas relevantes para a reconstrução e a explanação dos fenômenos, nas condições em que forem considerados.

Ao primeiro grupo de operações, correspondem certas técnicas de investigação, que asseguram ao investigador a possibilidade de constituir sua "documentação" (6). Essas técnicas variam, naturalmente, de acordo com a natureza da pesquisa empreendida, mas algumas são de utilização universal nas ciências sociais. Nas pesquisas de reconstrução histórica, as técnicas empregadas para o levantamento dos dados brutos são as mesmas que as utilizadas pelos historiadores. Nas pesquisas de campo é que a observação direta de ocorrências, formas de atuação social e situações de vida encontra larga aplicação. Contudo, mesmo 
nessa fase, a observação direta não se confunde com a mera "verificação" passiva do que ocorre no mundo ambiente, Não só o sujeito-investigador interage ativamente com os sujeitos-observados, como ele próprio orienta suas observações para centros de interesses criados pela situação de pesquisa. Além disso, a própria posição do investigador pode ser manipulada estrategicamente, com o fito de proporcionar-lhe perspectivas mais favoráveis à observação direta da realidade. A prática da "observação participante", por exemplo, sob dissimulação dos propósitos reais do investigador ou na condição de investigadorresidente ( 7 ), facilita o acesso ao mundo íntimo dos sujeitos-investigados, reduz as barreiras emocionais ou morais à observação e estimula a projeção endopática do observador nas atitudes, concepções de vida e valores sociais estranhos. Os principais meios de investigação na pesquisa de campo são, porém, técnicas de observação indireta, como a entrevista, o estudo de caso (de personalidades de grupos ou de instituições sociais), o questionário e o formulário. Nas pesquisas que podem realizar-se sob modelos experimentais, algumas dessas técnicas de investigação são associadas à observação controlada e dão margem ao recurso mais amplo à mensuração de atitudes, de opiniões e do comportamento manifesto ( 8 ).

O segundo grupo de operações repousa em manipulações através das quais o sujeitoinvestigador organiza, critica e classifica a "documentação" levantada. A natureza da pesquisa apresenta pouca importância aqui, pois as mesmas técnicas de organização, crítica e classificação dos dados podem ser aplicadas, indiferentemente, a materiais levantados por meio da pesquisa de reconstrução histórica, da pesquisa de campo ou da pesquisa experimental. A única diferença fundamental diz respeito às observações quantificáveis, que podem ser submetidas a tratamento estatístico. Essas são, naturalmente, manipuladas de acordo com procedimentos especiais de expurgo, apuração e ordenação dos dados, fornecidos pela estatística. $\mathrm{O}$ investigador consegue determinar a significação relativa dos dados de fato, dentro do contexto empírico a que se integrem, mediante a análise da consistência dos diferentes tipos de informações e do grau de complementaridade delas no universo empírico observado. Em termos factuais, isso é obtido pela depuração crítica das informações, por seu tombamento sistemático (com frequiência pela organização de fichários), pelo levantamento e classificação das instâncias empíricas relevantes. Este último processo toma em consideração a importância intrínseca das instâncias empíricas selecionadas, suas relações evidentes com outras instâncias empíricas caracterizadas e sua presumível significação "teórica", isto é, sua importância hipotética, para a reconstrução e explanação dos fenômenos observados. No conjunto, a presente fase da observação assegura ao investigador: domínio prático sobre a "documentação" efetivamente útil para fins científicos; maior confiança nos dados de fato, selecionados para tratamento analítico ulterior; e um conhecimento prévio das possibilidades abertas pela "documentação" para atingir os alvos empíricos e teóricos da investigação.

O terceiro grupo de operações abrange os procedimentos propriamente analíticos, que são peculiares à observação científica. Ele compreende duas categorias distintas de atividades intelectuais. De um lado, a construção do que se poderia chamar, de acordo com Burguess ( 9 ), de tipos empíricos, que produzem o fenômeno concreto no estado em que ele é considerado pela investigação científica. De outro, a descoberta e a evidência de propriedades dos fenômenos que não são acessíveis, de modo imediato, às modalidades já referidas de observação direta ou indireta.

A construção do tipo empírico é conseguida por meio de procedimento de indução enumerativa ( ou "indução aristolética", entendendo-se que na formação da inferência só são relevantes os caracteres essenciais na manifestação do fenômeno). Alguns autores, como Znaniecki ( 10 ), criticam severamente as limitações da indução enumerativa nas ciências sociais. Contudo, a crítica deles é pertinente apenas em um ponto. É que os resultados da indução enumerativa constituem um mero momento do processo de observação da realidade. $\mathrm{O}$ investigador que se limitar à exposição de semelhantes resultados terá deixado, obviamente, de conduzir a investigação empreendida a seus fins completos. Todavia, ela constitui um recurso indisponível da observação, porque dá ao sujeitoinvestigador a possibilidade de converter, analiticamente, verificações sobre atributos ou propriedades dos fenômenos em conhecimentos primários sobre os fenômenos considerados como um todo. Por isso, cabe à indução enumerativa, como instrumento do processo de reconstrução analítica, oferecer os meios através dos quais se passe do fenômeno concreto, tal como pode ser 
percebido pelos sentidos ou pelas técnicas que os complementam, ao fenômeno puro, tal como pode ser representado no nível genuinamente empírico.

O passo seguinte apresenta-se como a fase verdadeiramente crucial da observação nas ciências sociais e é o único que comporta confronto com a observação em condições experimentais. A representação dos fenômenos, através de exemplares empíricos puros, traduz um progresso enorme no conhecimento da realidade. Esta deixa de ser percebida como algo caótico e ininteligível, podendo ser descrita, pelo sujeito-investigador, por propriedades ou atributos essenciais, coerentes e interdependentes. Mas, não se pode dizer, desse conhecimento, que ele nos proporcione uma representação dos fenômenos nas condições de sua produção, consideradas pelo investigador. Para se conseguir isto, torna-se necessário submeter os fenômenos observados a novo tratamento analítico: ampliar os quadros da observação, de modo a repor os fenômenos reconstruídos em contextos empíricos nos quais eles sejam relacionados às variáveis que podem intervir em sua produção. Semelhantes resultados são obtidos, operacionalmente, por meio de processos analíticos de observação, que os cientistas sociais convencionaram chamar de "métodos" - o método monográfico, o método ecológico, o método histórico e o método estatístico ( 11 ).

Dessa forma, a observação é conduzida a seus alvos científicos fundamentais. Assim, por exemplo: após reconstruir os elementos nucleares de uma instituição, o investigador pode considerá-los através das condições de integração e do funcionamento da instituição, encarando-os à luz da composição interna da instituição reconstruída e das vinculações dela com outras instituições e com o sistema social inclusivo; depois de conseguir representar a distribuição no espaço de uma população com certos caracteres, o investigador pode indagar se essa distribuição se relaciona com padrões de ocupação do meio natural pela comunidade e como as relações evidenciadas se refletem, dinamicamente, na manifestação dos fenômenos investigados; tendo descoberto que certos efeitos sociais se produzem na forma de uma tendência irreversível, o investigador pode procurar saber quais são as condições estruturais e funcionais variáveis da vida social que regulam a produção e o encadeamento daqueles efetivos; havendo obtido certos índices, relativos à distribuição de determinados caracteres de uma população, ou certas tendências, resultantes dos valores assumidos por dado atributo durante certo lapso de tempo, o investigador pode realizar indagações no sentido de evidenciar as condições ou fatores responsáveis por tais regularidades. Portanto, o tratamento analítico dos fenômenos estudados alarga o campo de observação, tornado evidentes e inteligíveis os aspectos da realidade social que não são diretamente acessíveis às técnicas primárias de levantamento dos dados, e oferece meios precisos para a reprodução unitária das condições de manifestação dos fenômenos, significativas para a explicação científica.

Duas questões marginais se colocam aqui. A primeira, diz respeito ao uso do termo "método", para descrever as operações intelectuais, realizadas pelo sujeito-investigador ainda na fase da observação propriamente dita. Embora fosse melhor usar o termo "processo" ( 12 ), semelhante emprego da palavra parece justificar-se e é legítimo. Aliás, Wolf salienta que o termo método pode ser aplicado, no campo da ciência, tanto em sentido "técnico", quanto em sentido "lógico" (13). No primeiro caso, ele denota, naturalmente, as manipulações analíticas através das quais o investigador procura assegurarse condições vantajosas de observação dos fenômenos. Acresce que essas manipulações envolvem, nas ciências sociais, seja o recurso à indução enumerativa (na construção de tipos empíricos), seja a exploração da indução amplificadora (nos limites em que esta pode ser aplicada ao tratamento de instâncias empíricas representativas de um universo empírico mais amplo). Parece que as confusões poderiam ser evitadas, empregando-se as expressões "método de investigação" e "método de interpretação", respectivamente, nos níveis técnico e lógico.

A segunda, diz respeito à natureza do conhecimento obtido, no fim do processo de observação. É sabido que muitos projetos de pesquisa, nas ciências sociais, terminam praticamente aí. São os projetos ditos "monográficos", que fazem do conhecimento "descritivo", no nível mais rudimentar em que ele se confunde com a própria representação analítica das propriedades dos fenômenos e das condições de sua manifestação, o alvo essencial da investigação empírica. Não há duvida de que as evidências fornecidas pelas últimas fases da observação permitem alcançar tal alvo. Ao dispor de evidências para reconstruir exemplares empíricos puros dos fenômenos observados, o investigador dispõe das 
evidências necessárias para "descrevê-los" univocamente, no plano das exigências formais do conhecimento analítico. O que se pode dizer das explanações formuladas, é que elas só se aplicam e são válidas para o universo empírico no qual se concentrar a investigação. Isso decorre do fato de que a generalização científica não se confunde com a mera enumeração ou condensação das evidências descobertas, mesmo que a consistência e a validade empírica delas sejam conhecidas e a fórmula explanativa possua feição unitária. Todavia, é sabido que a importância lógica desse tipo de conhecimento repousa menos no que ele significa, em si mesmo, como possibilidade de "descrição" dos fenômenos sociais, que no que ele representa como etapa para se chegar a explicações positivas e empiricamente consistentes da realidade.

Embora o que interesse à ciência, realmente, sejam os projetos de pesquisa com propósitos teóricos, Hyman tem razão ao defender o ponto de vista de que não se deve subestimar esse tipo de investigação nas ciências sociais ( 14 ). Alguns especialistas, como Mannheim, por exemplo (15), temem que o acúmulo de materiais empíricos acabe ameaçando a ciência como tal. Contudo, parece contestável que tenhamos alcançado, nas ciências sociais, um nível de conhecimento positivo da realidade que torne inútil ou mesmo prejudicial a acumulação de materiais empíricos dessa natureza. Além disso, é preciso ter em mente que a interrupção da investigação, na fase em que é possível descrever univocamente o objeto das indagações, não impede nem prejudica a reelaboração teórica ulterior dos resultados conseguidos. É importante salientar isso porque esse tipo de investigação "descritiva" satisfaz às necessidades de conhecimento da realidade, comumente associadas a planos de tratamento dos problemas sociais, desenvolvidos e financiados por instituições filantrópicas ou de assistência social. O desinteresse por semelhante tipo de investigação poderia ser deveras prejudicial aos cientistas sociais, que perderiam oportunidades de financiamento do trabalho científico e uma das vias mais acessíveis de colaboração em tarefas práticas.

No momento, porém, a questão precisa ser encarada de outro ângulo. Considerando-se todas as atividades do investigador em um projeto completo de pesquisa, o processo de observação (como pode ser posto em prática atualmente nas ciências sociais), preenche a função de converter dados discretos e aparentemente caóticos em uma representação analítica, mas unitária e unívoca, das propriedades, natureza e condições de produção dos fenômenos, a que aqueles dados digam respeito. Pelo que já vimos, o referido processo confere ao observador a possibilidade de proceder metodicamente na investigação dos fenômenos sociais. Permite-lhe passar, gradualmente, dos dados perceptíveis pelos sentidos ou registráveis por meios técnicos para dados empiricamente consistentes e, destes, para aspectos da realidade que são essenciais à investigação científica. Por isso, compete-lhe organizar a experiência do investigador, com tal, e conduzir sua capacidade de interrogar a natureza humana, com seus fatores e produtos, até onde os sentidos e a inteligência não conseguem penetrar por si mesmos. Acima de tudo, cabe-lhe desvendar a matéria prima do raciocínio científico propriamente dito, transformando congéries de dados brutos em conjuntos ordenados de evidências empíricas precisas e de significação comprovada. Como essas evidências asseguram, objetivamente, a representação analítica dos fenômenos investigados e das condições de sua produção, elas constituem o verdadeiro ponto de partida e os únicos fundamento seguros da interpretação da realidade nas ciências sociais.

\section{III. - FUNDAMENTOS LÓGICOS DA ELABORAÇÃO DAS INSTÂNCIAS EMPÍRICAS}

Os resultados da discussão anterior sugerem que o processo de observação abrange algumas das fases mais importantes da pesquisa empírica sistemática. Mas, esta compreende, naturalmente, outras fases: aquela na qual o objeto da investigação é definido, que precede à observação propriamente dita; e o conjunto de fases em que o investigador procede à elaboração interpretativa das evidências empíricas e dos conhecimentos, descobertos durante o processo de observação. Esse encadeamento dos diversos grupos de fases da pesquisa empírica sistemática demonstra que há certa ordem nas diferentes operações intelectuais, que precisam ser realizadas pelo sujeito-investigador; e indica que estas operações são interdependentes, associandose e influenciando-se mutuamente, segundo um padrão regular de trabalho científico. Um dos problemas, colocados pelo encadeamento dos grupos de fases da pesquisa empírica sistemática e 
pela interdependência das operações intelectuais que eles envolvem, consiste em saber se a maneira de definir o objeto da investigação repercute no processo de observação e como isso se reflete nos alvos empíricos da observação.

Os especialistas em problemas da metodologia nas ciências sociais costumam ressaltar que a maneira de definir o objeto da pesquisa possui grande importância para o desenvolvimento das demais fases da investigação. Na verdade, a própria estrutura da pesquisa ( 16 ), a seleção e modo de levantar os fatos brutos e o estado em que os fenômenos são considerados na manipulação analítica desses fatos dependem, fundamentalmente, do sistema de referencia escolhido pelo investigador. Definindo os dados e as proposições que funcionarão como base da explanação ( 17 ), sistema de referência acaba delimitando os alvos teóricos da investigação, a natureza dela como contribuição científica "descritiva" ou "interpretativa" e as propriedades dos fenômenos ou as condições de sua produção que serão significativas para a análise. Por isso, as atividades cognitivas do investigador estão sujeitas, no decorrer do processo de observação, a duas espécies de determinações: a) tecnicamente, às normas que as regulam em termos das exigências formais da pesquisa empírica sistemática, as quais tendem a ser reconhecidas e praticadas de modo universal; b) metodologicamente, às implicações teóricas do projeto de pesquisa que, sendo impessoais, variam no entanto de um projeto a outro.

Limitando-nos ao segundo ponto, que nos interessa aqui, é evidente que os cientistas sociais se empenhariam em uma tarefa sem fim, se pretendessem esgotar, por meios exclusivamente empíricos, a realidade concreta, Znaniecki já demonstrou que, a esse respeito, a situação nas ciências sociais é similar à de qualquer disciplina científica (18). A realidade concreta é inexaurível e, tal como ela se oferece imediatamente ao observador, caótica e obscura. As proposições iniciais, ao definir os problemas científicos dos projetos de pesquisa, determinam quais são os aspectos da realidade a serem observados pelo sujeito-investigador e como deverão cair sob seu campo de observação. Isso significa que certos elementos subjetivos, essenciais para a organização da experiência do sujeito-investigador, são dados de antemão e orientam sua atividades cognitivas de caráter exploratório. Todavia, esses elementos subjetivos não se refletem na determinação do conteúdo da experiência, a não ser em um sentido dinâmico mas neutro: de colocar o sujeitoinvestigador em posições favoráveis à percepção, direta ou indireta, de ocorrências ou de processos que precisam ser registrados e reconstruídos. A única limitação apreciável, que mereceria ser lembrada no momento, consiste nas implicações seletivas das proposições iniciais. O conhecimento exaustivo de certo aspecto da realidade, digamos a natureza, as funções e as formas de manifestação do preconceito racial na sociedade brasileira, só poderia ser obtido mediante a realização de pesquisas cujas proposições iniciais estivessem, entre si, em relação de complementaridade.

O essencial, e que precisa ser retido na presente discussão, é que o sujeito-investigador não procede de forma arbitrária ou "livre", mesmo nas faces exploratórias da investigação. O levantamento de dados brutos, seu tratamento crítico e a manipulação analítica dos materiais com significação positiva ligam-se, de modo inelutável, a alvos cognitivos mais profundos e amplos, fornecidos pelas proposições iniciais dos projetos de pesquisa. Desde que o sujeito-investigador possua uma noção clara do que pretende "conhecer" e "explicar", impõe-se lidar com certos tipos de dados brutos; com as técnicas de investigação por meio das quais aqueles dados podem ser levantados, expurgados e classificados; e com os métodos de investigação adequados à natureza das evidências empíricas coligidas e ao seu tratamento analítico. Em particular, suas atividades cognitivas, como e enquanto observador, passam a inspirar-se em objetivos lógicos inerentes aos propósitos teóricos da pesquisa. Com isso, duas conseqüências importantes se revelam com nitidez. Primeiro, que a manipulação analítica dos dados brutos, a elaboração das instâncias empíricas relevantes para a construção de tipos empíricos e a formulação de "generalizações empíricas" ( 19 ) envolvem princípios lógicos, derivados do sistema de referência, implícita ou explicitamente explorado na pesquisa. Segundo, que todo projeto de pesquisa pressupõe um mínimo de princípios lógicos, que dão ao sujeito-investigador a possibilidade de reconstruir o concreto através de categorias abstratas, mas empiricamente válidas, produzidas por meio da análise. Quando o investigador omite os dados e as proposições que servirão como sistema de referência, ele apenas subestima certas indicações que são fundamentais para a derivação, por outros especialistas, dos princípios lógicos seguidos nas atividades cognitivas de caráter analítico. Nem por 
isso pode furtar-se a eles. O que ocorre, freqüentemente, é que semelhante negligência expõe o investigador ao risco de aproveitar mal os resultados da investigação para o progresso da teoria científica.

Os especialistas em metodologia das ciências sociais costumam, ainda hoje, atribuir pouca atenção a essas questões. Apenas onde foi possível aplicar modelos experimentais de pesquisa ou onde a análise estatística logrou condições efetivamente favoráveis de aproveitamento é que elas foram devidamente apreciadas. O que se explica, naturalmente, pelo fato do planejamento da pesquisa exigir, nessas circunstâncias, uma definição precisa dos dados e das proposições iniciais da investigação. As questões mais discutidas dizem respeito aos critérios de formação da inferência indutiva enumerativa, em que se baseia a construção de tipos empíricos, e aos procedimentos de coligação dessa inferências em representações unitárias ("descrições" ou "generalizações empíricas", na linguagem corrente) de uniformidades reconhecíveis empiricamente. Assim, por exemplo, os tratados sobre técnicas e métodos de investigação tratam longamente do uso do método monográfico (20), procurando mostrar como se deve proceder à elaboração das instâncias empíricas para evidenciar propriedades e regularidades que podem ser caracterizadas empiricamente. O mesmo se faz com referência aos demais métodos de investigação, inclusive a estatística.

Entretanto, as descobertas feitas no plano da análise não são suficientes para a descrição completa e a explicação dos fenômenos investigados. Como vimos, elas dão margem a um conhecimento positivo sobre os caracteres fundamentais dos fenômenos observados e as condições de sua produção. Mas, esse conhecimento não pode ser estendido a fenômenos que não pertençam ao universo empírico considerado, ainda que possuam os mesmos caracteres e se produzam em condições similares. O próprio conhecimento fornecido pela amostragem cai nessa categoria, apesar de envolver procedimentos de indução amplificadora. As inferências estabelecidas com relação a um conjunto de indivíduos de uma população podem ser generalizadas a todos os indivíduos da população, tendo-se em vista os atributos observados. Todavia, esse conhecimento abstrato só se explica ao universo empírico abrangido pela amostra. Um conhecimento da mesma espécie, sobre situações similares, teria que ser obtido pela repetição do processo de amostragem. Ora, é essa dificuldade, exatamente, que se procura resolver, através de procedimentos de interpretação que generalizam, com fundamentos empíricos, os conhecimentos descobertos aos fenômenos que possuem os mesmos caracteres e se produzem em condições similares, independentemente de pertencerem ou não a um universo empírico determinado.

Daí decorre uma anomalia, sem dúvida transitória, que parece ser peculiar às ciências sociais. Na discussão dos problemas metodológicos, o emprego das técnicas e dos métodos de investigação e a utilização dos procedimentos de generalização raramente são apreciados como fases interdependentes da pesquisa científica. Revelamse, mesmo, duas tendências contraditórias: os especialistas norte-americanos devotam maior interesse aos problemas suscitados na primeira esfera; os especialistas europeus, ao contrário, dedicam maior atenção aos problemas que caem na segunda categoria. Todavia, nada justifica, atualmente, essa separação de centros de interesse na discussão dos problemas metodológicos das ciências sociais. $\mathrm{Na}$ verdade, a interdependência entre as últimas fases do processo de observação (nas quais as instâncias empíricas selecionadas são submetidas a tratamento analítico) e o processo de interpretação (no qual se trata de descrever e de explicar os fenômenos da forma mais abstrata possível)é garantida, factual e logicamente: a) pelas implicações teóricas das proposições iniciais, que definem o objeto das pesquisas; b) pela natureza das evidências empíricas, que se tornam acessíveis ao investigador somente a partir dos resultados cognitivos da reconstrução analítica da realidade.

Quanto às implicações teóricas, é preciso salientar que o mesmo grupo de princípios básicos, associados aos dados e proposições iniciais do projeto de pesquisa, é válido e se aplica igualmente a todas as atividades do investigador. Em consequiência, não existem descontinuidades lógicas que sejam produzidas pela transição de uma fase a outra da pesquisa. $O$ raciocínio do investigador se ajusta, operacionalmente, à natureza variável das atividades intelectuais desenvolvidas em cada uma das fases, mas sempre de acordo com o referido grupo de princípios básicos (cuja reformulação, quando ocorre, passa a ter a mesma vigência geral). Por isso, no tratamento analítico das instâncias empíricas cruciais o investigador retém os caracteres do fenômeno observado nos estados em que ele irá interessar à interpretação sintética e generalizadora. 
A elaboração das instâncias empíricas, mesmo servindo aos propósitos específicos da reconstrução analítica da realidade, vincula-se, indiretamente, a alvos lógicos mais amplos, definidos pelos objetivos teóricos da pesquisa.

Quanto à natureza das evidências, é obvio que a síntese e a explicação generalizadora seriam totalmente impossíveis sem o tratamento analítico prévio dos dados de fato e a acumulação dos conhecimentos proporcionados pela reconstrução empírica da realidade. Foi um dos grandes méritos de Marx ter posto isso em relevo, ao debater os problemas metodológicos da economia ( 21 ). Segundo indica explicitamente, a análise proporcionaria às ciências sociais um equivalente da experimentação. Seus resultados é que permitiriam reproduzir o concreto através do pensamento e explicar a realidade de forma sintética. Essa formulação ainda hoje é atual. Apenas se poderia acrescentar que o processo de síntese e amplificação envolve um novo nível de abstração e de generalização. As evidências empíricas deixam de ser relacionadas aos universos empíricos restritos, por intermédio dos quais elas são descobertas e selecionadas, para serem referidas, in genere, aos fenômenos cujas propriedades e estados elas caracterizam tipicamente.

A superação dessa anomalia depende, naturalmente, do progresso da pesquisa empírica sistemática nas ciências sociais. Só nessa direção é possível conceber-se maior entrosamento entre teoria e pesquisa e a constituição de um padrão de trabalho realmente unificado, capaz de coordenar organicamente todas as tarefas do investigador em um projeto completo de pesquisa. Enquanto isso não ocorrer, a elaboração das instâncias empíricas poderá ser mais ou menos dissociada dos alvos fundamentais do conhecimento científico, com real prejuízo para o desenvolvimento das ciências sociais.

(continua)

\section{NOTAS}

(*) O presente trabalho foi escrito em janeiro de 1957, para o Colóquio sobre Metodologia das Ciências Sociais, organizado pelo Dr. Antônio Jorge Dias no Centro de Estudos Políticos e Sociais, de Lisboa. Foi publicado na revista Anhembi $n^{\circ} 82$. Setembro de 1957.

(1) A destinação entre "ciência de observação" e "ciência experimental" é difícil de fazer-se, porque todo o conhecimento científico se funda, direta ou indiretamente, na observação. A forma de praticar a observação e de utilizá-la como instrumento de descoberta ou de controle é que varia. Nesse sentido, apenas, apresenta certo interesse essa velha distinção, que levou Claude Bernard a afirmar que "a observação é a investigação de um fenômeno natural, e a experiência é a investigação de um fenômeno modificado pelo investigador" (Introduction a I'Êtude de la Médicine Expérimentable, Les Éditions du Cheval Ailé, Genebra, 1945, págs. 66-67). Contudo, salienta muito bem que a experimentação constitui uma forma artificial e provocada de observação e que o raciocínio científico (ou " raciocínio experimental", como prefere escrever). é o mesmo nos dois tipos de ciência.

( 2 ) Pauline V. Young, por exemplo, define a observação como "um estudo através da vista" (Cf. Scientific Social Surveys and Research, An Introduction to the Background, Content, Methods and Analysis of Social Studier, Prentice Hall, New York, 1939, pág. 118). Em regra, os especialistas em metodologia das ciências sociais restringem a fase de observação ao levantamento dos dados brutos (cf. também: George A. Lundberg, Social Research. A Study in Methods of Gathering Data, Longmans, Green, New York, London e Toronto, 1942, caps. I e II; Willian J. Goode e Paul K. Hatt, Methods in Socia Research, McGrawHill Book, New York, London e Toronto, 1952, cap 10). Onde é possível o emprego da observação controlada, porém, dá-se maior importância aos meios ativos de que dispõe o investigador para descobrir, inclusive analiticamente, as condições relevantes na manifestação dos fenômenos (cf. esp. Helen Peak, "Problems of Objetive Observation", in Leon Festinger e Danier Katz (eds.), Research Methods in the Behavioral Sciences, Staples Press, London, 1954, págs. 243-299; e Roger W. Heys a Alvin F. Zander, "Observation of group Behavios", págs. 381-417). Até o presente, só François Simiand tentou sugerir, explicitamente, a utilidade da análise como instrumento de observação dos fenômenos sociais; mas, infelizmente, focalizou com maior interesse as questōes que dizem respeito à lógica da explicação científica (cf. Le Salaire, l'Évolution Sociale et la Monnaie. Essai de Théorie Expérimentale du Salaire, Librairie Félix Alcan, Paris, 1932, vol. I, págs. X-XXIX e 5-137; vol. II, pág 531 e seguintes). Contudo, não deixou de salientar o que é mais importante no que concerne às operações intelectuais que dão ao cientista social o verdadeiro acesso às condições em que os fenômenos se produzem.

( 3 ) William I. Thomas e Florian Znaniecki, The Polish Peasant in Europe and America. Monograph on an Immigrant Group, Richard G. Badger, The Gorham Press, 1918-1920; vol. I, págs. $1-86$.

( 4 ) John Madge, The Tools os Social Science, Longmans, Green, London, New York e Toronto, 1953, pág. 124.

( 5 ) Essas operações podem ser separadas, de acordo com suas funções na constituição do raciocínio científico. As primeiras, dizem respeito aos processos através dos quais a realidade é investigada; as segundas, aos processos de formação da inferência e de explicação da realidade. Com base em semelhantes diferenças é que Wolf procura distinguir as duas noções fundamentais de "método" no pensamento científico, aplicando à primeira a qualificação de "métodos técnicos" e, à segunda, a de "métodos lógicos" ( cd. Wolf, Textbook of logic, George Allen \& Unwin, $2^{\mathrm{a}}$ ed., London, 1938, págs. 33-34).

(6) Essas técnicas tem sido amplamente estudadas pelos especialistas em metodologia das ciências sociais. O leitor encontrará uma rica bibliografia a respeito no mencionado livro de Pauline V. Young (cd. Scientific Social Surveys and Research, págs. 535-598).

( 7 ) Em regra, os especialistas discutem as vantagens da observação participante tendo em vista a dissimulação dos propósitos do pesquisador em suas relações com os membros do grupo investigado. Todavia, os resultados de James West, em seu estudo sobre Plainville, demonstram que a segunda alternativa merece maior consideração por parte dos investigadores (cf. James West, Plainville, U.S.A., Columbia University Press, New York, 1945; veja-se também, Florestan Fernandes e Ramzia Gattas, "A História de Vida na Investigação Sociológica: A Seleção dos Sujeitos e suas Implicações", in 
Sociologia, vol. XVIII, n. 2, SP, 1956, especialmente, págs. 128134).

( 8 ) O leitor encontrará um balanço das principais tentativas de aplicação de modelos experimentais de observação nas ciências dos trabalhos de Gardner Murphy, Lois Barclay Murphy e Theodore M. Newcomb, Experimental Social Psychology. An Interpretation of Research upon the Socialization of individual, Harper \& Brother Publishers, New York e London, ed. rev. 1937; J. L. Moreno, Fondements de la Sociométrie, trad. de H. Lesage e P. H. Maucorps, Presses Universitaires de France, 1954; F. Stuart Chapin, Experimental Desings in Sociological Research, Harper \& Brothers Publishers, New York e London, 1947.

(9) Cf. Ernest W. Burgess, "Methodes de la Recherche Sociologique" in Cahiers Internationaux de Sociologie, vol. I, 1946, especialmente, págs. 28-29.

( 10 ) Florian Znaniecki, The Method of Sociology, Farrar \& Rinehart, New York, 1934, págs. 221 e seguintes.

( 11 ) Para referências bibliográficas, conforme a indicação fornecida na nota 6 .

( 12 ) Conforme Paul Arbousse-Bastide, "Os Métodos, os Processos e as Técnicas da Pesquisa Sociológica: Aplicações às Relações entre História e Sociologia", in Sociologia, vol. II, n. 4, SP, 1940, págs. 305-327.

(13) Veja-se a nota 5.

( 14 ) Herbert Hyman, Survey Design and Analysis. Principles, Cases and Procedures, The Free Press, Publishers, Glencoa, Illinois, 1955, cf. págs. 2-3, especialmente.

( 15 ) Karl Mannheim, American Sociology", in Essays on Sociology and Socialo Psicology, Routledge \& Kegan Paul, London, 1953, pág. 102.

(16) Veja-se em H. Hyman, a caracterização e o contraste da "investigação descritiva" e da "investigação explanatória" (cf. Survey Design and Analysis, op. cit., págs. 83-89 e partes II-III.

(17) Cf. Felix Kaufmann, Metodologia de las Ciencias Sociales, tradução de Eugênio Imaz, Fondo de Cultura Economica, México, 1946, págs. 93.

(18) Cf. Florian Znaniecki, The Method of Sociology, op. cit., 1934, cap. I, SS 2 e3.

( 19 ) A noção de "generalização empírica" refere-se a uniformidades sociais, conhecidas analiticamente (cf. esp. Robert K. Merton, Social Theory and Structure. Toward the Codification of Theory and Research, The Free Press of Glencoe, Illinois, 1949, págs. 91-92). Adiante, para facilidade de expressão, usaremos o conceito de caracterização empírica em sentido inclusivo, abrangendo tanto o conhecimento analítico concernente aos tipos empíricos, quanto o relativo a uniformidades sociais.

( 20 ) Às vezes também designado como "estudo de caso", principalmente pelos especialistas norte-americanos e ingleses. Aquela expressão parece-nos adequada sempre que se trata da coleta de dados; no nível da análise, impõe-se o uso da expressão "método monográfico", já consagrada nas ciências sociais e, desde Le Play, tão vinculada aos problemas da sociologia descritiva.

(21) Consulte Karl Marx, Crítica da Economia Política, Tradução de Florestan Fernandes, Editora Flama, São Paulo, 1946, pág. 219 e seguintes. 